\title{
On energy constraints on housing development
}

\author{
Aleksey Pestryakov, Nadezhda Sbrodova*, and Mariya Albycheva \\ Ural State University of Economics, 620144, 8 Marta Str., 62, Ekaterinburg, Russia
}

\begin{abstract}
The article examines the dependence of the "smart home" technology on the technical capabilities of the engineering infrastructure. Home automation ideas have been evolving since the early 20th century. However, this technology is not widespread yet due to a number of features of the system. We consider the dependence of the reliability of the system on the characteristics of external power grids. There are technological developments in housing construction sphere that make it possible to maximize the satisfaction of the needs of residents. At the same time, the irrational distribution of capacities, the unpredictability (for operating organizations) of territorial development plans, and increased consumer demands hinder the use of modern technologies.
\end{abstract}

\section{Introduction}

The sustainable development of society is based on the introduction of new technical solutions: new programs, new equipment, new specialties. When introducing innovations, under the influence of euphoria, one can forget about the limitations that the state of the infrastructure component imposes on any production. Let us consider the impact of infrastructure on one of the promising areas of digital technology development such as "smart home". At many scientific conferences in recent years, researchers have brought up various issues that arise in connection with the design of the system $[6,7,10]$. Application in practice has revealed new areas that require attention of developers and operators. We are considering the relationship between the requirements of the "Smart Home" system and the technological capabilities of external power grids.

\section{Main part}

"Smart home" is a system for the automation of a residential or commercial facility. The term "smart home", which has become a household name for home automation systems, was coined in 1984 by the American National Association of Home Builders. It is a system of devices capable of performing daily household chores without human intervention. Adjusting the level of lighting and heating, heating water and food, fire and burglar alarms and much more functions do not require a lot of mental power for making a decision, therefore, they can be calculated using the simplest algorithms.

\footnotetext{
* Corresponding author: n-vs@yandex.ru
} 
The ideas of a "smart home" began to spread to the masses from the beginning of the 20th century, with the appearance of the first household appliances powered by electricity. The massive introduction of personal computers into the life of society has increased the desire to delegate to household equipment not only the physical performance of certain operations, but also managerial decisions about their expediency depending on changes in external conditions. Standards for the control of home appliances with the transmission of signals over the electrical network and over the radio channel appeared. Now the Internet is widely used to transmit control signals.

Photo relays, motion sensors (Fig. 1, 2) are often associated with a "smart home". They are used to turn on the lighting when the illumination level drops below the permissible level or at movement detecting in the area of the sensor. Similar devices for remote control of individual devices are available from many electronics manufacturers. Control signal transmission devices are quite simple, their installation does not require the involvement of highly qualified specialists. However, they cannot be called a "smart home" in the full sense of the word. These are just separate elements of the system, usually not connected, and sometimes even incompatible with each other.

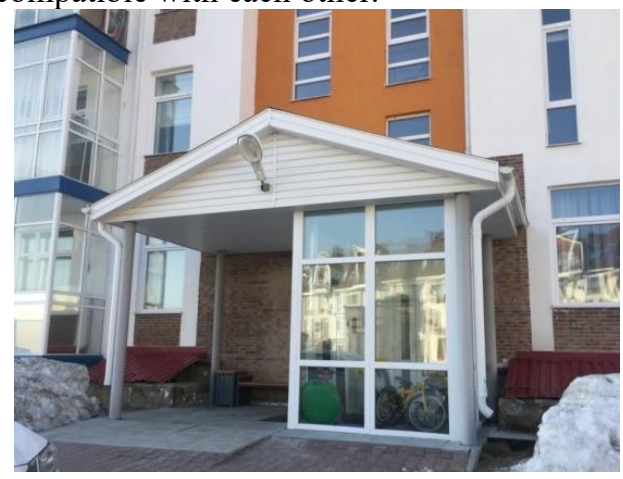

Fig. 1. Entrance group to an apartment building with the lighting controlled by a photo relay

"Smart home" means not only turning on and off certain devices under certain conditions, but also automatic control of the operation of lighting, ventilation, access, video surveillance, heating, fire alarm systems, etc. Alternatively stated, the "smart home" ensures the performance of routine control and management functions that take up a lot of time during the everyday operation of a residential building. The living environment becomes more comfortable and economical, which makes it consistent with the requirements of sustainable development.

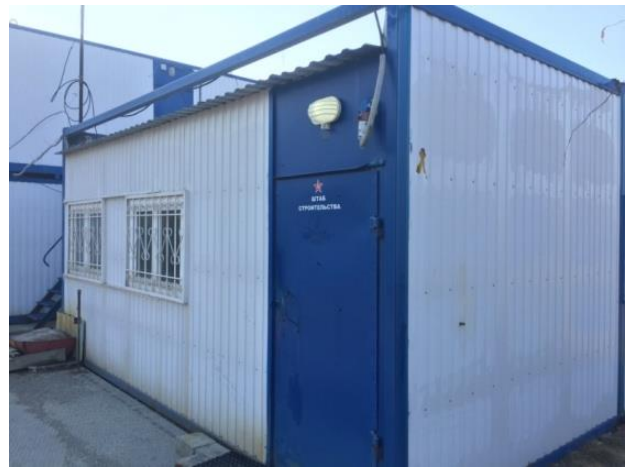

Fig. 2. Lighting above the entrance controlled by a motion sensor 
"Smart home" is not only a fashionable trend, it is also a fairly large market share. The turnover of the world market for equipment and services integrated into smart home systems reached 96 billion dollars in 2018 and continues to grow at a rate of $10-14 \%$ per year [9]. For decades, there has been a process of streamlining the management of home appliances and devices through the creation of national and international standards and protocols. In 1975, a single standard X10 was developed for the management of smart home systems in the UK, which is still popular today. In 1999, the EIB / KNX European Bus standard for communication of building automation devices was adopted, which has become international since 2006. There are other standards, but there is still no uniform principle for organizing a control network. Accordingly, the control signal can be transmitted both over the power grid and over twisted pair or radio frequency. At present, $\mathrm{Wi}-\mathrm{Fi}$ is often used for these purposes. The use of various types of equipment causes large differences in project implementation costs.

When the question of a smart home arrangement arises, it is said that in Russia the main obstacles to the development of such technologies are poverty and low awareness of the population, as well as a poorly developed market for Internet services. We propose to supplement this list with infrastructure constraints. As it has been already mentioned, the main impetus for the development of the "smart home" system was the appearance on the market of appliances powered by electricity. Electricity is still the main source of energy for most household appliances and equipment. Let us consider the issue of supplying power to a standard home. The power of the electricity provided to the property by the supplier is determined by the availability of resources, the ability to transfer energy to the property and the ability of the property to receive it.

The first task facing the user of the "smart home" system is the organization of a reliable power supply, that is, the problem of maintaining the parameters of the supplied electricity in time. In the Russian Federation, the PUE-7 (Electrical Installation Rules), approved by Order of the Ministry of Energy of Russia dated 08.07.2002 No. 204, are in force. According to the clause 1.2.18 of this normative act, all power receivers are divided into three categories of power supply reliability (Table 1).

Table 1. Categories of electrical receivers on the basis of reliability

\begin{tabular}{|c|c|c|}
\hline $\begin{array}{l}\text { Category } \\
\text { number }\end{array}$ & Which electrical receivers are covered by & Design standards and devices \\
\hline 1 & $\begin{array}{l}\text { An interruption in the power supply of which } \\
\text { may entail a danger to human life, a threat to } \\
\text { the security of the state, significant material } \\
\text { damage, disruption of a complex } \\
\text { technological process, disruption of the } \\
\text { functioning of especially important elements } \\
\text { of communal services, communication and } \\
\text { television facilities. }\end{array}$ & $\begin{array}{l}\text { Must be supplied with electricity from two } \\
\text { independent mutually redundant power sources. } \\
\text { A break in their power supply in the event of a } \\
\text { power failure from one of the power sources can } \\
\text { be allowed only for the time of automatic power } \\
\text { restoration. }\end{array}$ \\
\hline $\begin{array}{l}1 \\
\text { (special) }\end{array}$ & $\begin{array}{l}\text { The uninterrupted operation of which is } \\
\text { necessary for a trouble-free shutdown of } \\
\text { production in order to prevent a threat to } \\
\text { human life, explosions and fires. }\end{array}$ & $\begin{array}{l}\text { Additional power shall be provided from a third } \\
\text { independent mutually redundant power supply. }\end{array}$ \\
\hline 2 & $\begin{array}{l}\text { An interruption in the power supply of which } \\
\text { leads to a massive undersupply of products, } \\
\text { massive downtime of workers, mechanisms } \\
\text { and industrial transport, disruption of the } \\
\text { normal activities of a significant number of } \\
\text { urban and rural residents. }\end{array}$ & $\begin{array}{l}\text { Must be supplied with electricity from two } \\
\text { independent mutually redundant power sources. } \\
\text { Power supply interruptions are allowed for the } \\
\text { time required to turn on the backup power by the } \\
\text { actions of the personnel on duty or the mobile } \\
\text { operational brigade. }\end{array}$ \\
\hline 3 & $\begin{array}{l}\text { All other electrical receivers that do not fall } \\
\text { under the definitions of the first and second } \\
\text { categories. }\end{array}$ & $\begin{array}{l}\text { Power supply can be performed from one power } \\
\text { source, provided that the power supply } \\
\text { interruptions necessary for repair or replacement } \\
\text { of a damaged element of the power supply } \\
\text { system do not exceed one day. }\end{array}$ \\
\hline
\end{tabular}


Table 5.1. SP 31-110-2003 indicates that all residential buildings (multi-storey, blocked, individual) fall under the 2 nd and 3rd reliability categories [3]. According to Table 1, for these objects, a power outage is allowed for up to one day. However, the use of the "smart home" system does not allow a power outage, regardless of the duration of emergency situations. There are technical solutions to this issue on the market. For example, inverter systems that provide power to the boiler, pumps and other household equipment necessary for the life support of the premises for up to one day [5]. Although, the use of this equipment requires significant costs for its purchase and installation, which dramatically increases the cost of the project.

The second issue of energy supply is the capacity allocated to the facility. The problem is that the power required for the uninterrupted operation of electrical equipment and the power allocated to the facility are two different quantities.

On the base of the regulatory framework in the design and construction of residential buildings, residential apartments/ houses are divided by the allocated capacity into categories 1 and 2. For residential buildings of the 2nd category, an electric power of 8.8-11 $\mathrm{kW} / \mathrm{h}$ is allocated for an apartment or a block house, and for an individual residential house $10-15 \mathrm{~kW} / \mathrm{h}$ [4]. If the owner wishes to provide more power, he must transfer the house to the 1st category, since the first category is not standardized for the allocated power. However, this category applies only if there are technical connectivity options, which is determined not only by the state of the electrical equipment of the premises, but also by the state of external power grids. Even in the absence of their significant wear and tear, the power supply organization, not knowing the prospects for the development of the territory, usually lays down a reserve of capacities for peak loads and does not allocate the maximum possible power to electric consumers.

The estimated maximum permissible power can be determined either by the technical specifications (TU) for connection, or based on the marking of the input machine to the dwelling. The power calculation for the equipment used is carried out according to the formula:

$$
P_{\max }=U^{*} I^{*} 0,8,
$$

where $\mathrm{U}=220 \mathrm{~V}$ is the rated voltage in the network;

0.8 - phase shift of three-phase alternating voltage;

I - standard current determined by the power of the input machine into the premises (Fig. 3).

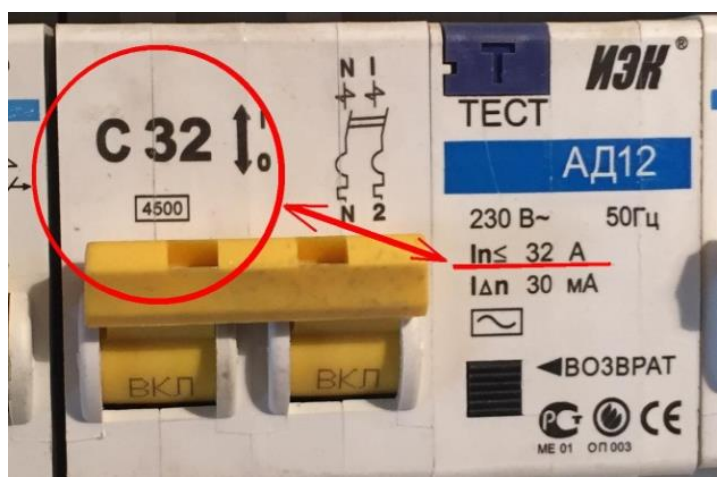

Fig. 3. The relationship between the brand of the input machine and the maximum current in the network

For the example shown in Fig. 3, the maximum power will be:

$$
P \max =U * I * 0.8=220 * 32 * 0.8=5.6 \mathrm{~kW}
$$


When designing the load, it is necessary to compare the data obtained according to the technical specifications with the required design capacity. For this, the peak load of all equipment used is determined. Table 2 shows averaged data for devices and equipment, taking into account the possibility of their joint operation.

Table 2. Average power of household electrical appliances

\begin{tabular}{|c|l|c|}
\hline № & \multicolumn{1}{|c|}{ Name of devices } & $\begin{array}{c}\text { Power (average), } \\
\mathbf{k W} / \mathbf{h o u r}\end{array}$ \\
\hline 1 & Refrigerator & 0,2 \\
\hline 2 & Hotplate & 4 \\
\hline 3 & Iron & 1 \\
\hline 4 & TV-set & 0,2 \\
\hline 5 & Washing machine & 3 \\
\hline 6 & Vacuum cleaner & 1 \\
\hline 7 & Dishwasher & 2 \\
\hline 8 & Microwave oven & 2,5 \\
\hline 9 & Air conditioner & 0,6 \\
\hline 10 & Computer & 0,2 \\
\hline 11 & Cooker hood & 0,1 \\
\hline 12 & LED lamp & \\
\hline
\end{tabular}

Note: For the table, averaged data according to the data of the sites of equipment manufacturers are used. Heating devices are not considered.

In addition, since the range of used household equipment is very wide, the load can be determined for the outlet network.

The outlet load can be calculated using the formula:

$$
\text { Pp.p }=\text { Pp * np * } 0.9
$$

where Pp.p is the rated power for the outlet network;

Pp - design power of one outlet $(0.1 \mathrm{~kW} / \mathrm{h})$;

$\mathrm{np}$ is the number of sockets;

0.9 is the coefficient of simultaneous operation for a network of outlets with a quantity of 10 to 20 pieces.

Summing up the capacity of the equipment used at the same time, we must take into account the growth prospects of the used capacity. Capacity reserve is up to $30 \%$. The equipment sharing ratio is 0.8 .

The third issue in the implementation of the "smart home" system is the delegation of decision-making authority.

Even an approximate calculation shows that the amount of power allocated to the house is often inferior to the amount of needs.

It is a common situation when at start up of additional equipment, the input machines into the apartment are turned off due to overload. In this case, the owner of the premises usually turns off unnecessary equipment and turns on the starting machine (fuse/switch) again. In the "smart home" system, this decision should be made by the automation using an uninterruptible power supply device (inverter). That is, control devices must have a built-in algorithm that allows you to understand the cause of what happened and turn off the equipment that is unnecessary in this situation. There should be a ranking of the load, which implies the presence of a powerful computing complex that determines the algorithm of control actions, that increases the costs even more.

In order to reduce costs, the owners tend to ignore the above issues necessary to be resolved when introducing a "smart home" system. This results in equipment shutdown in the premises. If the life support systems (heating, water supply) are configured centrally (for example, by the management company), then this case is not critical. If the systems in the premises are autonomous, then their blackout for a long period can lead to the collapse of the entire facility. 
Here are excerpts from the developer's response to the owner's claim on the fact that the gas boiler stopped during a temporary power outage by the electricity supplier: "In response to your claim from ... year, about a breakdown of a gas boiler, we report the following:

In accordance with paragraph ... and paragraph ... of the act of acceptance of the premises, engineering and technical equipment has been transferred to you, including external and internal networks of water supply, heating, gas, sewerage, power supply. The equipment and communications of the residential building have been checked by the parties and are in good condition.

During the commission inspection of a residential building with your participation, the following was found: the gas boiler and heating radiators are not connected to the power grid, the water supply and heating systems, including the gas boiler, are filled with water, the pipeline elements have ruptures due to freezing water in them.

In accordance with parts 3 and 4 of Article 30 of the Housing Code of the Russian Federation, the owner of a residential premises bears the burden of maintaining this premises and is obliged to maintain this premises in good condition, preventing mismanagement with it, respect the rights and legitimate interests of neighbors, the rules for using residential premises, and also the rules for maintaining the common property of owners of premises in an apartment building.

Based on the foregoing, we inform you that the responsibility for malfunctions in the operation of the gas boiler and water supply and heating systems is borne by the owner of the Residential House from the date of signing the acceptance certificate of the Residential House. "

To prevent this situation, the owner simply had to turn on the automation after the power supply was restored. The owner was absent for several months, and the inability to perform one action led to the failure of the heating system of the house and, as a result, to high costs for repair work.

Thus, when planning the increasingly popular "smart home" system, designers and owners usually pre-set high requirements for electrical supply at the lowest possible cost of maintaining the system. While, created in accordance with the current regulatory requirements, the energy infrastructure to which housing construction objects are connected is not able to guarantee the required uninterrupted operation and power reserve. As a result, the organization operating the network refuses the owner to issue permission to install the smart home system.

\section{Conclusion}

The infrastructural energy component is one of the key links in the development of housing construction. There are technological developments in housing construction that make it possible to maximize the satisfaction of the needs of residents. At the same time, the irrational distribution of capacities, the unpredictability (for operating organizations) of territorial development plans, and increased consumer demands hinder the use of modern technologies. Significant capital investments are required in the development of power grids, which will make it possible to reserve energy capacities for the introduction of new promising line of development.

\section{References}

1. Housing Code of the Russian Federation

2. PUE-7. Electrical Installation Rules, http://www.docload.ru/Basesdoc/7/7177/index.htm 
3. SP 31-110-2003 Design and installation of electrical installations for residential and public buildings, http://docs.cntd.ru/document/1200035252

4. Temporary instructions for calculating electrical loads of residential buildings RM 2696-01

5. Uninterruptible power supplies for home and cottage, http://www.vegavolt.ru/application/uninterrupted-power-supply-house-cottage/

6. L.Sh. Kadyrova, Int. scientific research J., 5-3 (2013)

7. V.Yu. Karnitsky, S.V. Ershov, A. Yu. Ryumov A.Yu., Izvestia TulGU, 12(1) (2017)

8. A.E. Kitaev, I.I. International Journal of Open Information Technologies, 10 (2017)

9. RBK Research Store, https://marketing.rbc.ru/research/39016/

10. V.A. Rychkova, Bulletin of Science and Education, 4(58) (2019) 